\title{
Mudanças no uso da terra decorrentes da expansão da cultura da cana-de-açúcar na região oeste do estado de São Paulo
}

\author{
Land use change from the sugar cane expansion \\ in the western region of São Paulo state, Brazil
}

\section{Wagner Luiz Lourenzani ${ }^{I}$ Marcellus Marques Caldas ${ }^{I I}$}

\section{RESUMO}

A demanda por alternativas energéticas tem aumentando a produção mundial de biocombustíveis e, consequentemente, o cultivo das culturas agrícolas. No Brasil, o lançamento dos veículos bicombustiveis propiciou a retomada da importância da produção de etanol e, consequentemente, numa nova fase de expansão do cultivo de cana-de-açúcar. Diversas questões relacionadas à sustentabilidade da produção de biocombustíveis têm sido discutidas na literatura, tais como o efeito na produção de alimentos e na segurança alimentar, o impacto ambiental da mudança do uso da terra e os efeitos sociais no campo. Este trabalho pretende analisar as mudanças no uso da terra na região Oeste Paulista, provocadas pela expansão do cultivo da cana-de-açúcar. Na última década (2003 a 2012), a região Oeste Paulista representou mais da metade da expansão dessa cultura no estado de São Paulo, maior estado produtor brasileiro. O método utilizado foi o Modelo Shift-Share, que, por meio da decomposição da variação das áreas, possibilitou calcular os efeitos escala e substituição das principais atividades em análise. Este trabalho revela que a expansão da cultura da cana-de-açúcar na região estudada ocorreu predominantemente pela substituição de áreas de pastagem e, consequentemente, da atividade pecuária.

Palavras-chave: cana-de-açúcar, expansão, mudança do uso da terra.

\section{ABSTRACT}

The demand for energy alternatives to oil are increasing global biofuel production and, consequently, the biofuel crops cultivation. In Brazil, the emergence of flex-fuel vehicles resumed the importance of ethanol production, resulting in a new phase of Brazilian sugar cane crop expansion. Several issues related to the sustainability of biofuel production have been discussed in the literature, such as the effect on food production and food security, the environmental impact of land use change and social effects in the field. This study aims to analyze the land use change in the Oeste Paulista region, caused by the expansion of sugar cane cultivation. Between 2003 and 2012, the Oeste Paulista region represented more than half of the expansion of this crop in São Paulo state, the largest producer in Brazil. This paper used the Shift-Share model to decompose the agricultural areas variation and to calculate the replacement of the main activities analyzed. The results revealed that, in the analyzed region, the expansion of sugar cane area has occurred predominantly by replacing pasture and, consequently, by cattle activity.

Key words: sugar cane, expansion, land use change.

\section{INTRODUÇÃO}

O preço do petróleo, a poluição do ar, a exaustão previsível das fontes não renováveis de energia e o impacto climático dos combustíveis fósseis têm moldado as estratégias dos governos na busca de fontes de energia renováveis e menos poluentes (DUFEY, 2006; FARGIONE et al., 2008). A energia renovável apresenta vantagens por estar amplamente disponível, polui menos, garante a disponibilidade de suprimento e reduz a dependência do petróleo e das regiões produtoras politicamente instáveis (GOLDEMBERG, 2007). Dentre as fontes renováveis, os biocombustíveis são aqueles obtidos a partir da biomassa; ou seja, matérias-primas de origem animal ou vegetal (NASS et al., 2007).

O desenvolvimento do biocombustível, que surgiu na interface da agricultura e da energia, tem sido considerado como um dos desenvolvimentos agrícolas mais significativos dos últimos anos (FAO,

\footnotetext{
IPrograma de Pós-graduação em Agronegócio e Desenvolvimento (PGAD), Universidade Estadual Paulista (UNESP), Av. Domingos da Costa Lopes, 780, 17602-496, Tupã, SP, Brasil. E-mail: wagner@tupa.unesp.br. Autor para correspondência.

"Kansas State University (KSU), Manhattan, KS, USA. 
2013a). A demanda por alternativas energéticas têm aumentando a produção mundial de biocombustíveis e, consequentemente, o cultivo das culturas agrícolas usadas na sua produção (FARGIONE et al., 2008).

No cenário mundial, o Brasil apresenta elevada competitividade na produção de biocombustíveis, especialmente, o etanol de cana-deaçúcar. Suas vantagens competitivas e comparativas se devem à disponibilidade de recursos naturais (terra, água e radiação solar), de tecnologia (produção e processamento) e de mão de obra (MARTINELLI \& FILOSO, 2008; NASS et al., 2007; GOLDEMBERG et al., 2008).

O interesse dos países desenvolvidos em soluções mais limpas para o setor de transporte e o lançamento dos veículos bicombustíveis (flex fuel), no ano de 2003, propiciou a retomada, no país, da importância da produção de etanol e, consequentemente, numa nova fase de expansão do cultivo de cana-de-açúcar no Brasil (NASS et al., 2007). A ampliação da área plantada, das plantas industriais e a construção de novas usinas resultam de decisões da iniciativa privada (CAMARGO et al., 2008). Tais ações são também fortemente estimuladas por políticas públicas, com suporte financeiro estatal, de apoio à produção, à infraestrutura industrial, viabilizando, até mesmo, a exportação dos produtos. A partir da visão mundial sobre a importância dos biocombustíveis nas matrizes energéticas, destaca-se a recente estrangeirização dos investimentos (terras, produção agrícola e usinas) no setor sucroalcooleiro nacional (SAUER \& LEITE, 2012).

O Brasil é o maior produtor mundial de cana-de-açúcar, de açúcar e o segundo maior produtor de etanol (FAO, 2013b; RFA, 2013). No mercado internacional, o Brasil é o maior exportador de açúcar e etanol. Na safra 2011/2012, produziu cerca de 560 milhões de toneladas de cana-de-açúcar, 36 milhões de toneladas de açúcar e 23 bilhões de litros de etanol (PROCANA, 2012). O estado de São Paulo tem sido o representante mais importante desse setor. Em 2011, o estado paulista representou cerca de 54\% da produção nacional de cana-de-açúcar, 59\% de açúcar e 55\% de etanol (PROCANA, 2012).

A produção brasileira de etanol cresceu $180 \%$, entre 2005 e 2011 , com um consequente incremento de 3,8 milhão de hectares de cana-deaçúcar. O estado de São Paulo representou 56\% da expansão nacional (PROCANA, 2012; IBGE, 2013). Entretanto, esse processo não ocorreu homogeneamente em todo o território estadual, em função da saturação de áreas nas regiões de produção mais antigas e pela busca de regiões com condições edafoclimáticas mais adequadas (CAMARGO et al., 2008). A expansão da área plantada tem sido muito mais expressiva na região oeste do estado (RUDORFF et al., 2010).

Diversas questões relacionadas à sustentabilidade da produção de biocombustíveis têm sido discutidas na literatura. As discussões estão centradas na percepção dos impactos em diferentes dimensões, como o potencial efeito na produção de alimentos e na segurança alimentar (AJANOVIC, 2011; FAO, 2013a; ZILBERMAN et al., 2013); o impacto ambiental e da mudança do uso da terra (RAGHU et al., 2006; FARGIONE et al., 2008; SPAROVEK et al., 2009, TSAO et al., 2012) e os efeitos sociais no campo (MOL, 2007; MORAES, 2007; BAPTISTA, 2012).

Portanto, todo esse processo acarreta transformações complexas, com efeitos multidimensionais em uma determinada região. Nesse contexto, este trabalho se limita a verificar um desses efeitos - a transformação da paisagem agrícola na região oeste do estado de São Paulo. Assim, o principal objetivo é analisar as mudanças no uso da terra na região supracitada, no período de 2003 a 2012, provocadas pela expansão do cultivo da canade-açúcar. Especificamente, pretende-se analisar as alterações na composição agropecuária, identificando quais atividades incorporaram e/ou cederam área na região Oeste Paulista.

\section{MATERIAL E MÉTODOS}

O recorte geográfico adotado neste trabalho é a denominada região Oeste Paulista (Figura 1). Essa região é definida a partir da seleção dos municípios de 11 Escritórios de Desenvolvimento Rural (EDRs) localizados no oeste do estado (CAMARGO et al., 2008). Os EDRs são agrupamentos de municípios regionalizados pela Secretaria de Estado de Agricultura e Abastecimento, que divide o estado de São Paulo em 40 regiões.

Para analisar espacialmente a dinâmica de expansão da cultura da cana-de-açúcar na região Oeste Paulista, foi utilizado um sistema de informação geográfica (SIG). Para o desenvolvimento desse sistema, foram utilizados arquivos geoespaciais disponibilizados pelo IBGE Mapas (2013). Dados obtidos por meio do Projeto CANASAT (2013) foram inseridos no SIG para tratamento e análise.

Para identificar a alteração da área agricultável na região Oeste Paulista, no período de 2003 a 2012, utilizou-se o Modelo Shift-Share (SANTOS et al., 2008; CAMARGO et al., 2008). Esse modelo parte do princípio de que a área 


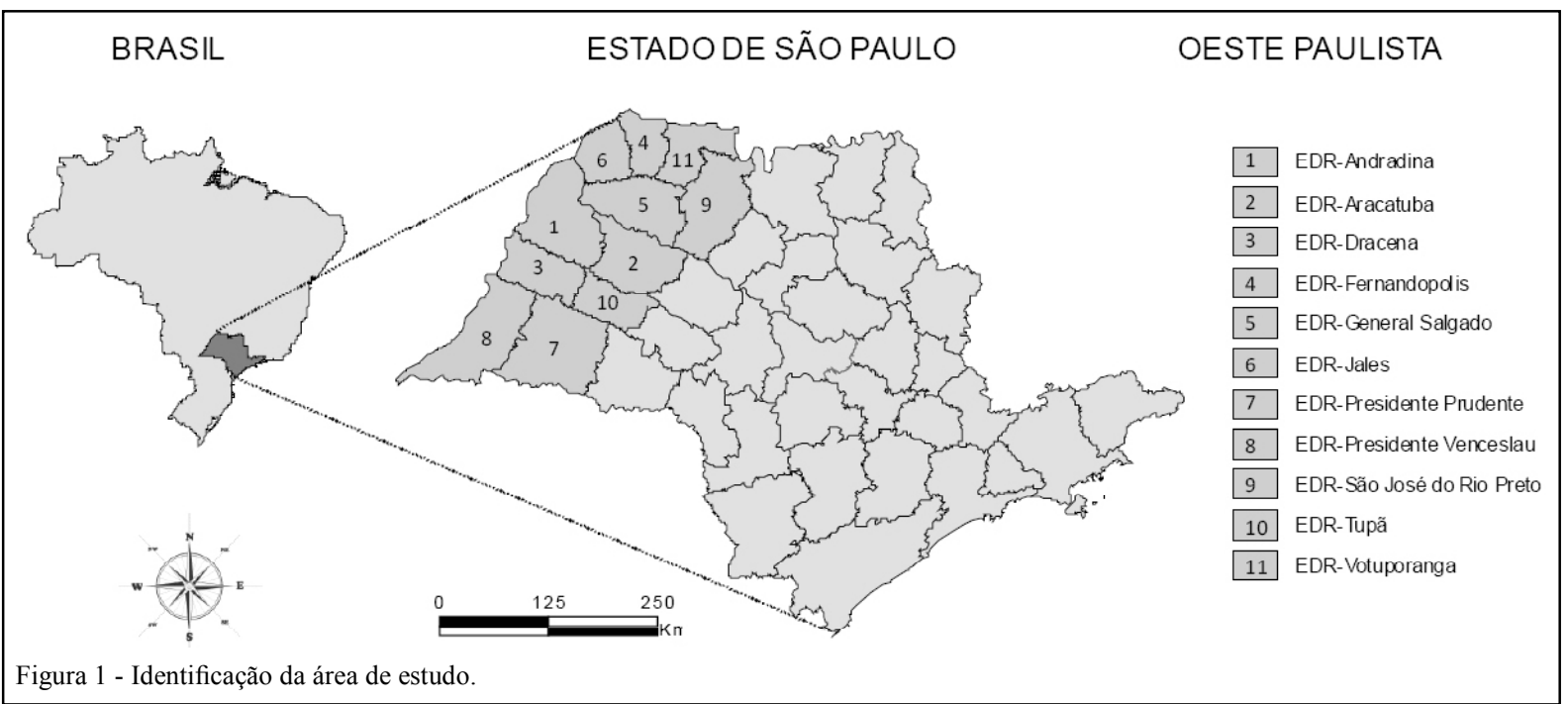

agricultável se modifica em um determinado período, devido à alteração do tamanho ou escala do conjunto formado pelas atividades que concorrem pelo fator terra, ou pela substituição de um produto por outro dentro desse conjunto.

Por meio da decomposição da variação da área, é possível calcular os efeitos escala e substituição das principais atividades em análise. O modelo analítico utilizado é representado pela expressão:

$$
A_{i 2}-A_{i 1}=\left(\alpha A_{i 1}-A_{i 1}\right)+\left(A_{i 2}-\alpha A_{i 1}\right)
$$
em que:

$A_{i 2}-A_{i 1}=$ variação da área cultivada com uma atividade " $i$ ", entre o período 1 e 2 ; efeito-substituição $\left(\alpha A_{i 1}-A_{i 1}\right)=$ efeito-escala; e, $\left(A_{i 2}-\alpha A_{i 1}\right)=$ sendo:

$$
\alpha=A_{t 2} A_{A_{t 1}} \quad A_{t 1}=\sum_{i} A_{i 1} \quad A_{t 2}=\sum_{i} A_{i 2}
$$

em que, $A_{t 1}$ e $A_{t 2}$ são as áreas totais ocupadas com as $\mathrm{n}$ atividades agropecuárias de uma região, respectivamente, nos anos 1 e 2 .

O Efeito-Escala (EE) é dado pela variação na área de uma atividade, por meio das alterações de tamanho ou escala dos sistemas, mantendo inalterada sua participação dentro deste. Valores positivos e negativos representam, respectivamente, tendências de expansão ou contração do sistema analisado. De acordo com SANTOS et al. (2008), os valores do efeito-escala para cada atividade mostram como seria o comportamento dessas se a ampliação ou a contração da área fosse distribuída de forma uniforme entre elas.

O Efeito-Substituição (ES) mostra a variação da participação de uma atividade dentro do sistema, revelando se esta substituiu ou foi substituída por outras atividades. Um valor positivo desse efeito revela que uma atividade substituiu outras atividades, que tiveram um efeito-substituição negativo.

Esse modelo baseia-se na hipótese da proporcionalidade, em que as áreas cedidas por determinadas culturas são proporcionalmente distribuídas para aquelas que expandiram suas áreas. Portanto, segundo CAMARGO et al. (2008), trata-se de um método indicativo e não determinístico, com a capacidade de identificar tendências dos movimentos de substituição.

Os dados utilizados para essa análise advêm de séries históricas das áreas cultivadas de produtos de origem vegetal e de pastagens dos EDRs que compõem a região Oeste Paulista. Os dados, referentes ao período entre 2003 e 2012, foram obtidos por meio do levantamento sobre a produção agropecuária do estado de São Paulo, realizado pelo Instituto de Economia Agrícola - IEA, em conjunto com a Coordenadoria de Assistência Técnica Integral - CATI (IEA, 2013).

\section{RESULTADOS E DISCUSSÃO}

O processo de expansão do cultivo de cana-de-açúcar ocorreu de forma heterogênea entre os municípios da região Oeste Paulista. Na figura 2, é possível verificar a dinâmica de expansão da cultura da cana-de-açúcar por município, no período entre 2003 e 2012, bem como as áreas de ocupação (expansão e renovação) por EDR.

No período analisado, a cultura da canade-açúcar avança na ocupação de todo o território da região Oeste Paulista, e aumenta sua participação, 

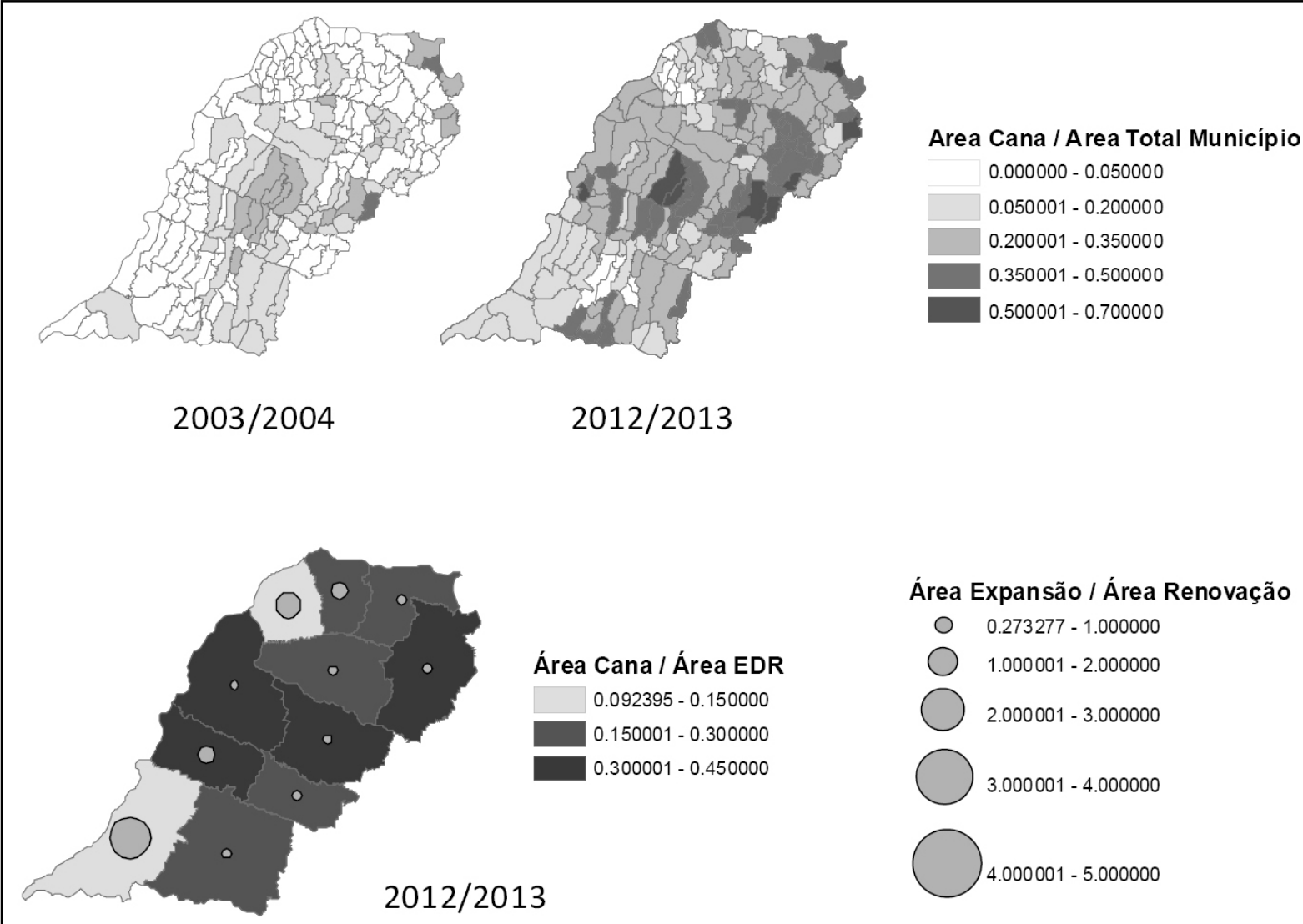

Fonte: elaborado a partir dos dados CANASAT (2013).

Figura 2 - Expansão do cultivo da cana-de-açúcar, por município, entre as safras de 2003/04 a 2012/13; Área de ocupação, em porcentagem, e a razão entre área de expansão e renovação de cana-de-açúcar, por EDR, na safra 2012/13.

ano após ano, no uso da terra dos municípios. Verifica-se que o avanço se dá em direção ao oeste da região. Enquanto a região central apresenta a maior concentração de cultivo de cana-de-açúcar da região estudada, as regiões sudoeste e noroeste apresentam os menores índices de ocupação.

Quando analisada sob a ótica dos EDRs, verifica-se que, na safra 2012/2013, as maiores concentrações de cultivo de cana-de-açúcar estão localizadas nos EDRs de Araçatuba (40\%), de São José do Rio Preto (33\%), de Andradina (32\%) e de Dracena (30\%). Entretanto, esses índices de ocupação ainda estão abaixo das tradicionais áreas de cultivo de cana no estado de São Paulo, onde se atinge 50\% do território (RUDORFF et al., 2010). Os EDRs de Jales e Presidente Venceslau apresentam a menor porcentagem de ocupação de cana, apresentando, respectivamente, $9 \%$ e $12 \%$.

A razão entre a área de expansão e de renovação revela o quão nova é a área de cultivo. $\mathrm{O}$ EDR de Presidente Venceslau apresenta uma relação de 4,60. Isso significa que, na safra 2012/2013, apresenta 4,6 vezes mais área de expansão do que de renovação. Os EDRs de Jales e Fernandópolis também apresentam mais áreas novas, com índices de 2,6 e 1,7, respectivamente. As demais regiões apresentam índices menores ou iguais a 1, revelando áreas mais antigas, com áreas de renovação maiores do que de expansão.

Considerando a continuidade desse processo de expansão, tais resultados sugerem que as regiões que apresentam os menores índices de concentração de cana-de-açúcar, e as menores razões entre área de expansão/renovação, são as mais propensas a receberem novos investimentos em cultivo dessa cultura. Nesse contexto, para a região estudada, encontram-se nessa situação os EDRs de Presidente Venceslau e Jales.

A tabela 1 apresenta os resultados das análises sobre os efeitos escala e substituição, propiciando a visualização das modificações na composição agropecuária na região Oeste Paulista.

Ciência Rural, v.44, n.11, nov, 2014. 
Tabela 1 - Efeitos escala (EE) e substituição (ES) da região Oeste Paulista, entre 2003 e 2012.

\begin{tabular}{|c|c|c|c|c|c|c|}
\hline \multirow{2}{*}{ OESTE PAULISTA } & \multicolumn{2}{|c|}{------- Área Cultivada (ha) -------- } & \multicolumn{2}{|c|}{--------- Variação da Área ---------- } & \multirow{2}{*}{$\begin{array}{l}\text { EE } \\
\text { (ha) }\end{array}$} & \multirow{2}{*}{$\begin{array}{l}\text { ES } \\
\text { (ha) }\end{array}$} \\
\hline & 2003 & 2012 & (ha) & $(\%)$ & & \\
\hline Cana-de-açúcar & 550.584 & 1.925 .914 & 1.375 .330 & $249,79 \%$ & -5.671 & 1.381 .001 \\
\hline Mata natural & 205.766 & 297.209 & 91.442 & $44,44 \%$ & -2.119 & 93.562 \\
\hline Seringueira & 24.386 & 63.167 & 38.781 & $159,03 \%$ & -251 & 39.032 \\
\hline Eucaliptos & 20.045 & 51.364 & 31.319 & $156,24 \%$ & -206 & 31.525 \\
\hline Cerradão e cerrado & 102.194 & 113.139 & 10.945 & $10,71 \%$ & -1.053 & 11.997 \\
\hline Capim para semente & 25.918 & 29.389 & 3.471 & $13,39 \%$ & -267 & 3.738 \\
\hline Cana para forragem & 27.949 & 30.668 & 2.719 & $9,73 \%$ & -288 & 3.007 \\
\hline Banana & 8.593 & 11.423 & 2.830 & $32,93 \%$ & -89 & 2.918 \\
\hline Amendoim & 26.792 & 29.330 & 2.538 & $9,47 \%$ & -276 & 2.814 \\
\hline Laranja & 74.475 & 75.044 & 569 & $0,76 \%$ & -767 & 1.337 \\
\hline Mandioca & 13.390 & 12.700 & -690 & $-5,15 \%$ & -138 & -552 \\
\hline Tomate & 3.374 & 1.904 & -1.469 & $-43,55 \%$ & -35 & -1.434 \\
\hline Manga & 4.600 & 1.699 & -2.901 & $-63,06 \%$ & -47 & -2.853 \\
\hline Abacaxi & 3.741 & 0 & -3.740 & $-100,00 \%$ & -39 & -3.702 \\
\hline Arroz & 5.909 & 421 & -5.488 & $-92,88 \%$ & -61 & -5.427 \\
\hline Outros Produtos & 21.140 & 14.495 & -6.645 & $-31,43 \%$ & -218 & -6.427 \\
\hline Sorgo & 13.597 & 5.449 & -8.148 & $-59,93 \%$ & -140 & -8.008 \\
\hline Café & 42.233 & 18.437 & -23.797 & $-56,35 \%$ & -435 & -23.361 \\
\hline Soja & 112.000 & 83.386 & -28.614 & $-25,55 \%$ & -1.154 & -27.460 \\
\hline Algodão & 33.024 & 3.787 & -29.237 & $-88,53 \%$ & -340 & -28.897 \\
\hline Pastagem natural & 138.466 & 99.543 & -38.923 & $-28,11 \%$ & -1.426 & -37.497 \\
\hline Feijão & 59.454 & 11.680 & -47.773 & $-80,35 \%$ & -612 & -47.161 \\
\hline Milho & 291.817 & 146.361 & -145.457 & $-49,85 \%$ & -3.006 & -142.451 \\
\hline Pastagem cultivada & 4.334.294 & 3.053 .948 & -1.280 .346 & $-29,54 \%$ & -44.645 & -1.235 .701 \\
\hline TOTAL & 6.143 .739 & 6.080 .456 & -63.283 & $-1,03 \%$ & & \\
\hline
\end{tabular}

Fonte: IEA (2013).

A sistematização apresenta uma análise com 23 atividades, que representavam, entre 2003 e 2012, 99,7\% da área total das atividades agropecuárias da região Oeste Paulista.

Observa-se que, no período analisado, a área cultivável da região Oeste Paulista se manteve praticamente a mesma. Entre 2003 e 2012, houve uma pequena redução de aproximadamente 63 mil hectares, ou $1 \%$ da área total. Destaque deve ser dado, pelo crescimento percentual, para as culturas da cana-de-açúcar (250\%); seringueira (159\%); e eucaliptos $(156 \%)$. As culturas que mais decresceram percentualmente foram o abacaxi (100\%), arroz (93\%) e o feijão (89\%). Entretanto, ao se considerar a variação nominal das áreas, revela-se, de forma preeminente, o crescimento de 1,375 milhão de hectares da cultura da cana e a redução de 1,280 milhão de hectares de pastagem cultivada.

As principais culturas que apresentaram efeito-substituição positivo foram a cana-deaçúcar, a mata natural, a seringueira e o eucalipto, representando cerca de $98 \%$ das áreas incorporadas.
As pastagens (cultivada e natural), o milho, o feijão, o algodão, a soja e o café (98\% das áreas cedidas) apresentaram efeito-substituição negativo.

A tabela 2 apresenta as alterações de áreas cultiváveis entre os produtos que incorporaram e cederam áreas na região no período estudado, baseado na análise de efeito-substituição. Além da predominante incorporação de áreas pela cultura da cana-de-açúcar (incluindo a cana para forragem), percebe-se que as atividades que mais incorporaram área foram as matas naturais e as florestas plantadas. Por outro lado, excetuando as áreas de pastagem (cultivada e natural), verifica-se que as atividades que cederam áreas são aquelas destinadas à produção de alimentos diversos, incluindo-se os produtos da cesta básica (arroz, feijão, mandioca, café).

A análise da atividade pecuária bovina na região Oeste Paulista revela que não houve aumento representativo na eficiência produtiva, no período entre 2003 e 2012. A redução de $29 \%$ da área de pastagem foi acompanhada por uma proporcional redução do número de bovinos - cerca de 1,8 milhão de cabeças 
Tabela 2 - Efeito-substituição atribuído aos produtos que cederam área, em hectares, na região Oeste Paulista, entre 2003 e 2012.

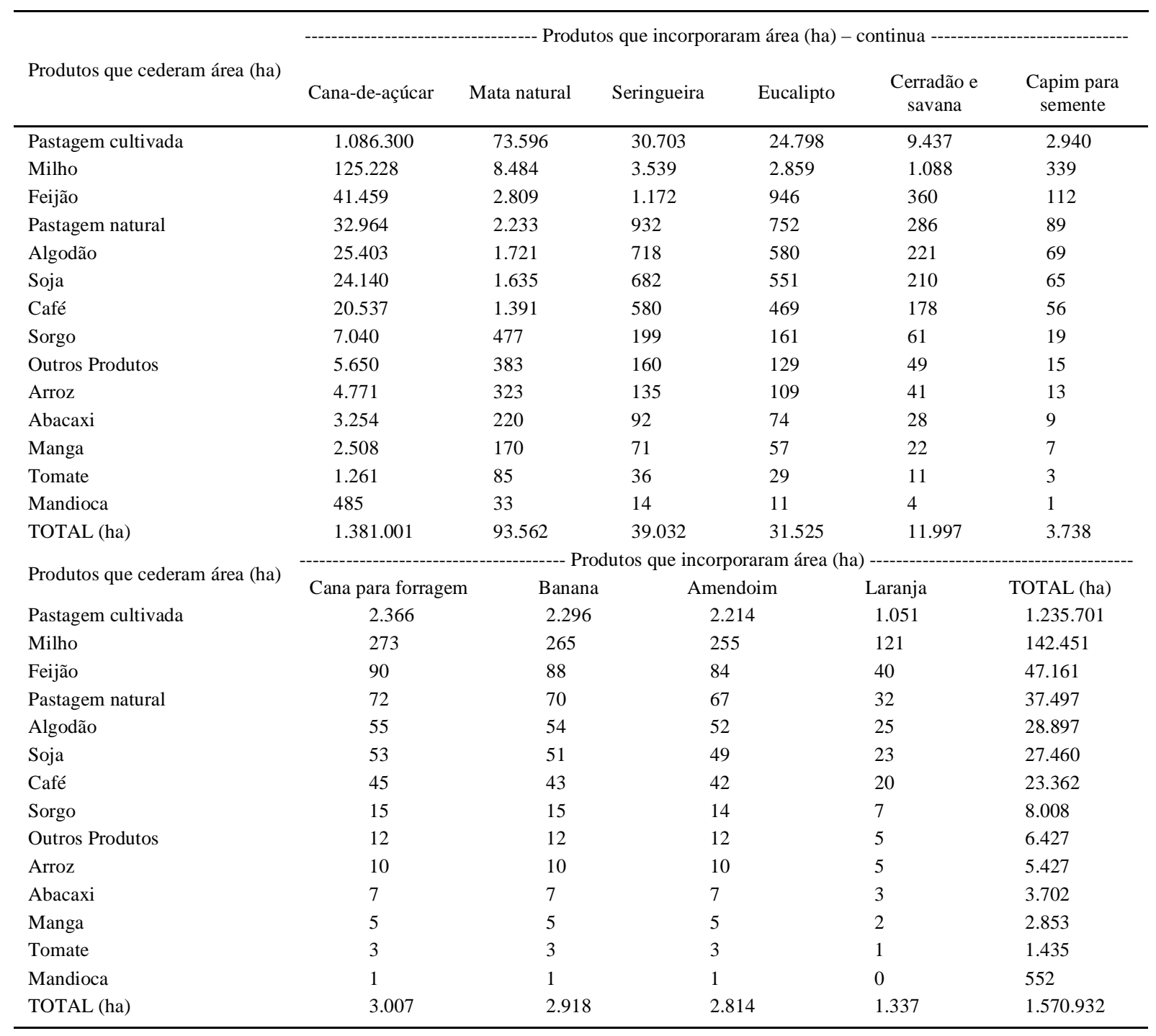

Fonte: a partir dos dados do IEA (2013).

(27\%). Em quase uma década, o rendimento passou de 1,49 para 1,55 cabeças por hectare.

\section{CONCLUSÃO}

Este estudo revelou que é crescente a participação e a importância da região Oeste Paulista no agronegócio sucroalcooleiro nacional e estadual. Destaque deve ser dado à disponibilidade de áreas e às condições edafoclimáticas que a região oferece para novas expansões. Além de estar dentro da área considerada como adequada para o Zoneamento Agroambiental para o setor sucroalcooleiro, as áreas de pastagens ainda prevalecem e, tanto a declividade predominante, quanto o clima da região, favorece o cultivo da cana-de-açúcar.

Sob a ótica da análise da alteração da composição agropecuária na região Oeste Paulista, pode-se afirmar que, no período entre 2003 e 2012, o processo de incorporação de área cultiváveis se dá, predominantemente, pela cultura da cana-de-açúcar em substituição às áreas de pastagens e, consequentemente, da atividade pecuária bovina. Tais resultados confirmam a continuidade da dinâmica de expansão apresentada por estudos anteriores (CAMARGO et al., 2008; RUDORFF et al., 2010). Em um patamar menos significativo, verifica-se a incorporação de áreas pelas atividades de matas e florestas plantadas, ao mesmo tempo em que se 
tem a redução de áreas de atividades de produtos agrícolas diversos destinados à produção de alimentos.

Embora a predominância da mudança do uso da terra na região oeste do estado de São Paulo tenha ocorrido pela incorporação de áreas de pastagens, não implica a inexistência de possíveis impactos sobre o acesso de alimentos em nível microrregional. Constata-se que outros produtos que apresentaram reduções de áreas foram aqueles característicos da pequena produção, tais como as frutas, tomate, mandioca, arroz, feijão e café. Ou seja, em regiões onde predomina a atividade rural familiar, a mudança da estrutura agrícola pode criar riscos à segurança alimentar, afetar a capacidade de produção das comunidades locais, impactar no preço da terra e na distribuição da renda agrícola (PEROSA, 2014).

Portanto, estudos mais aprofundados são necessários para verificar o efeito da expansão da cana-de-açúcar na agricultura familiar da região. Por fim, sugere-se a elaboração de estudos complementares (análise das externalidades sociais, econômicas e ambientais) para a região, considerando a interdisciplinaridade da temática e o horizonte temporal do processo de transformação.

\section{AGRADECIMENTO}

Fundação de Amparo à Pesquisa do Estado de São Paulo (FAPESP), Bolsa de Pesquisa - Exterior (Processo no 2011/22810-9), National Science Foundation (NSF).

\section{REFERÊNCIAS}

AJANOVIC, A. Biofuels versus food production: does biofuels production increase food prices? Energy, v.36, n.4, p.2070-2076, 2011. Disponível em: <http://www.sciencedirect.com/science/ article/pii/S0360544210002896>. Acesso em: 15 mar. 2013. doi: 10.1016/j.energy.2010.05.019.

BAPTISTA, R.D. Technological transition and the new skills required by the agribusiness sector. International Food and Agribusiness Management Review (Online), v.15A, p.105-109, 2012. Disponível em: $<$ http://www.ifama.org/files/\%252819\%252 9\%2520Baptista4.pdf>. Acesso em: 09 abr. 2013.

CAMARGO, A.M.M.P. et al. Dinâmica e tendência da cana-de-açúcar sobre as demais atividades agropecuárias, Estado de São Paulo, 20012006. Informações Econômicas, v.38, n.3, p.47-66, 2008.

CANASAT. Monitoramento da cana-de-açúcar via imagens de satélite. Disponível em: 〈http://www.dsr.inpe.br/laf/canasat/>. Acesso em: 14 abr. 2013.

DUFEY, A. Biofuels production, trade and sustainable development. London: International Institute of Environmental and Development, 2006. 57p.

FAO (UNITED NATIONS FOOD AND AGRICULTURE ORGANIZATION). Biofuels and the sustainability challenge: a global assessment of sustainability issues, trends and policies for biofuels and related feedstocks. Roma: Trade and Market Division, 2013a. 188p.

FAO (UNITED NATIONS FOOD AND AGRICULTURE ORGANIZATION). FAOSTAT. Disponível em <http://faostat. fao.org/ default.aspx>. Acesso em: 05 mai. 2013 b.

FARGIONE, J. et al. Land clearing and the biofuel carbon debt. Science, v.319, p.1235-1238, 2008. Disponível em: <http://www. sciencemag.org/content/319/5867/1235.full>. Acesso em: 17 abr. 2013. doi: $10.1126 /$ science. 1152747 .

GOLDEMBERG, J. Ethanol for a sustainable energy future. Science, v.315, p.808-810, 2007. Disponível em: <http://www. sciencemag.org/content/315/5813/808.full>. Acesso em: 24 mar. 2013. doi: $10.1126 /$ science. 1137013 .

GOLDEMBERG, J. et al. The sustainability of ethanol production from sugarcane. Energy Policy, v.36, p.2086-2097, 2008. Disponível em: <http://www.sciencedirect.com/science/article/pii/ S0301421508001080>. Acesso em: 15 mar.2013. doi:10.1016/j. enpol.2008.02.028.

IBGE (INSTITUTO BRASILEIRO DE GEOGRAFIA E ESTATÍSTICA). Disponível em: <http://www.ibge.gov.br>. Acesso em: 09 abr. 2013.

IEA (INSTITUTO DE ECONOMIA AGRÍCOLA). Estatísticas da produção agrícola. Disponível em: <http://ciagri.iea.sp.gov.br/nia1/ subjetiva.aspx?cod_sis=1\&idioma=1>. Acesso em: 30 abr. 2013.

MARTINELLI, L.A.; FILOSO, S. Expansion of sugarcane ethanol production in Brazil: environmental and social challenges. Ecological Applications, v.18, p.885-898, 2008. Disponível em: <http://www.esajournals.org/doi/full/10.1890/07-1813.1>. Acesso em: 19 abr. 2013.

MOL, A.P.J. Boundless biofuels? Between environmental sustainability and vulnerability. Sociologia Ruralis, v.47, n.4, p.297-315, 2007. Disponível em: <http://onlinelibrary.wiley.com/ doi/10.1111/j.1467-9523.2007.00446.x/full>. Acesso em: 5 abr. 2013. doi:10.1111/j.1467-9523.2007.00446.x.

MORAES, M.A.F.D. Indicadores do mercado de trabalho do sistema agroindustrial da cana-de-açúcar do Brasil no período 1992-2005. Estud. Econ., v.37, n.4, p.875-902, 2007. Disponível em: <http://www.scielo. $\mathrm{br} /$ scielo.php?script=sci_arttext $\&$ pid=S0101-41612007000400007 >. Acesso em: 29 mar. 2013. doi: 10.1590/S0101-41612007000400007.

NASS, L.L. et al. Biofuels in Brazil: an overview. Crop science, v.47, n.6, p.2228-2237, 2007. Disponível em: <https://www.crops. org/publications/cs/articles/47/6/2228>. Acesso em: 30 mar. 2013. doi:10.2135/cropsci2007.03.0166.

PEROSA, B.B. Impactos da expansão canavieira. Agroanalysis (FGV), v.34, p.24-26, 2014.

PROCANA. Anuário da Cana 2011 - Brazilian Sugar and Ethanol Guide. Ribeirão Preto: ProCana, 2012. 456p.

RAGHU, S. et al. Adding biofuels to the invasive species fire? Science, v.313, p.1742, 2006. Disponível em: <http://www. sciencemag.org/content/313/5794/1742.full.pdf >. Acesso em: 19 abr. 2013. doi: 10.1126/science.1129313.

RFA (RENEWABLE FUELS ASSOCIATION). World fuel ethanol production. Disponível em: <http://ethanolrfa.org/pages/ World-Fuel-Ethanol-Production>. Acesso em: 10 fev. 2013. 
RUDORFF, B.F.T. et al. Studies on the rapid expansion of sugarcane for ethanol production in São Paulo state (Brazil) using Landsat data. Remote Sensing, v.2, n.4, p.1057-1076, 2010. Disponível em: <http://www.mdpi.com/2072-4292/2/4/1057>. Acesso em: 15 fev 2013. doi:10.3390/rs2041057.

SANTOS, F.A.A. et al. Mudança da composição agrícola em duas regiões de Minas Gerais. Rev. Econ. Sociol. Rural, Brasília, v.46, n.3, p.579-595, 2008. Disponível em: <http://www.scielo. $\mathrm{br} / \mathrm{scielo} . \mathrm{php}$ ? pid=S0103-20032008000300001\& script $=$ sci arttext>. Acesso em: 03 mar. 2013. doi: 10.1590/S010320032008000300001.

SAUER, S.; LEITE, S.P. Expansão agrícola, preços e apropriação de terra por estrangeiros no Brasil. Rev. Econ. Sociol. Rural, v.50, n.3, p.503-524, 2012. Disponível em: <http://www.scielo.br/ scielo.php?script=sci_arttext $\&$ pid=S0103-20032012000300007>. Acessoem: 14 jan. 2014. doi: 10.1590/S0103-20032012000300007.
SPAROVEK, G. et al. Environmental, land-use and economic implications of Brazilian sugarcane expansion 1996-2006. Mitig Adapt Strateg Glob Change, v.14, p.285-298, 2009. Disponível em: <http://link.springer.com/article/10.1007/s11027-008-91643>. Acesso em: 01 abr 2013. doi: 10.1007/s11027-008-9164-3.

TSAO, C.C. et al. Increased estimates of air pollution emissions from Brazilian sugarcane ethanol. Nat. Clim. Change, v.2, p.5357, 2012. Disponível em: <http://www.nature.com/nclimate/ journal/v2/n1/full/nclimate1325.html>. Acesso em: 17 abr. 2013. doi:10.1038/nclimate1325.

ZILBERMAN, D. et al. The impact of biofuels on commodity food prices: assessment of findings. Am. J. Agr. Econ, v.95, p.2, p.275281, 2013. Disponível em: <http://ajae.oxfordjournals.org/content/ early/2012/06/07/ajae.aas037.full>. Acesso em: 17 abr. 2013. doi: 10.1093/ajae/aas037. 